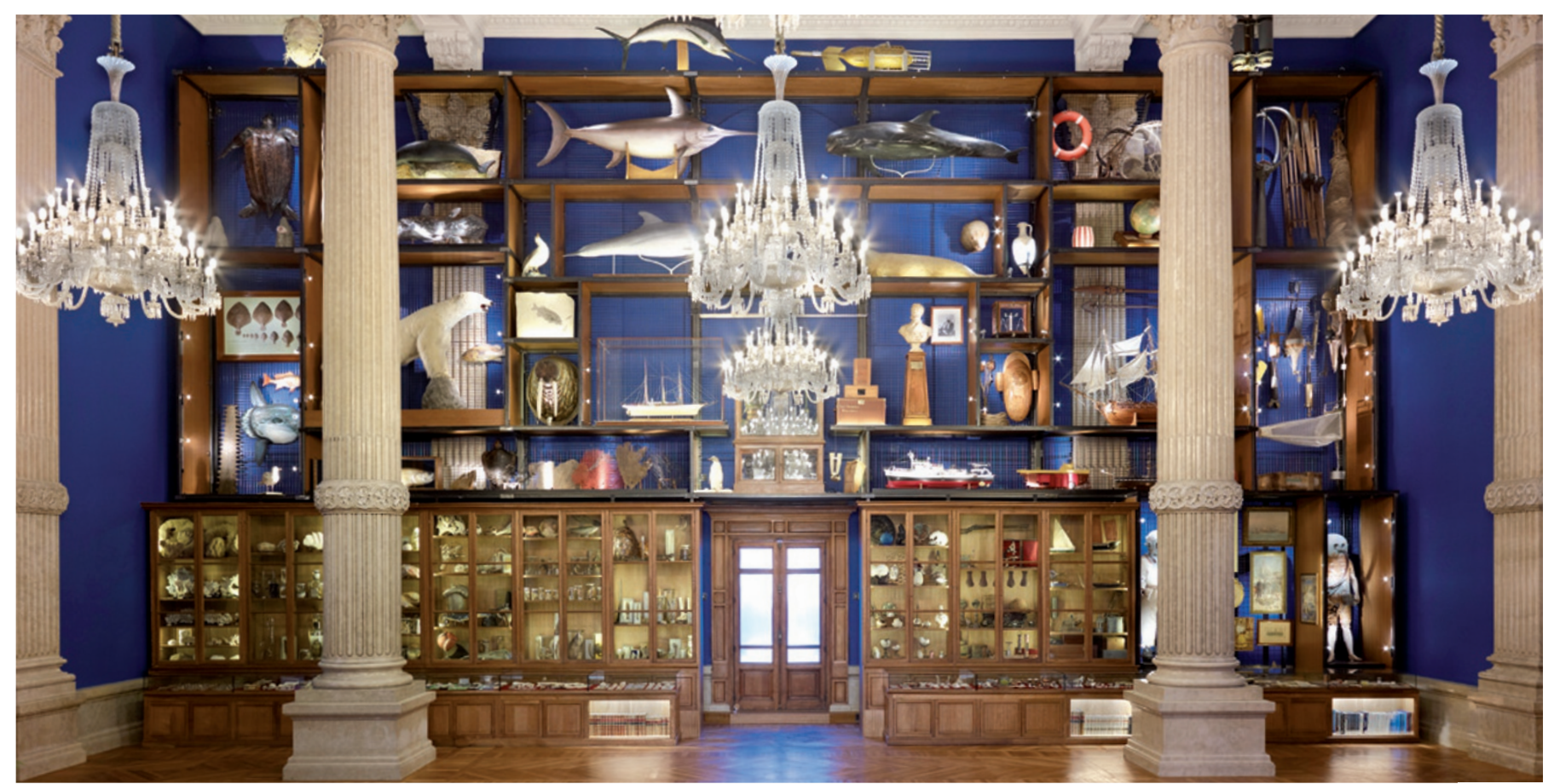

Mark Dion's cabinet of curiosities at the Oceanographic Museum of Monaco, illuminated by chandeliers modelled on zoologist Ernst Haeckel's jellyfish sketches.

ART

\section{Treasures fit for a prince}

\section{A Monaco exhibition showcases the marvels of the city-state's oceanic museum, discovers Alison Abbott.}

$\mathrm{L}$ ike many modern royals keen to demonstrate their relevance to society, Prince Albert II of Monaco has adopted a good cause - the protection of the marine environment. For his marriage on 2-3 July, he even tried to side-step protocol to hold his wedding dinner, not in his glamorous sixteenth-century palace, but inside the Oceanographic Museum of Monaco.

Clinging to a rocky cliff above the Mediterranean, the 1910 museum is a jewel in an anachronistic city-state scarred by shabby high-rises. Had its inadequate kitchens not scotched the prince's plans at the last minute, wedding guests would next weekend be dancing beneath antique chandeliers modelled on drawings of jellyfish and radiolaria by zoologist, artist and passionate Darwinist, Ernst Haeckel.

They could also have mingled with imposing modern artworks - including one of the world's largest oceanographic art installations, by US artist Mark Dion; and FrenchChinese artist Huang Yong Ping's 25-metre octopus-cuttlefish hybrid, whose tentacles curl around the main hall's marble columns. Dion's 'cabinet of curiosities' is part of a major exhibition, Oceanomania, of his and other artists' work, running at the museum until the end of September, and extending to the New National Museum of Monaco at the Villa Paloma.

Noted for its historic subterranean aquarium and its world-class research on coral, the Oceanographic Museum was founded by the prince's great-great grandfather, Albert I. It was run by the French Academy of Sciences until 2006, when its management returned to Monaco under Albert II, who wishes to unite within it scientific and artistic approaches to examining the ocean.

Dion is famous for his interest in collections of all kinds and was naturally drawn to the museum's splendid scientific collection. Albert I led 28 expeditions in the North Atlantic and Mediterranean between 1885 and 1915, and brought back all manner of exotic flora and fauna. These formed the museum's initial collection together with his oceanographic instruments. Extended by large acquisitions of objects and artworks, the holdings now exceed 400,000 items.
Oceanomania Oceanographic Museum and the New National Museum (Villa Paloma), Monaco. Until 30 September.
Dion scoured the collection for items to display in a giant cabinet of curiosity, or Wunderkammer, modelled on those of the sixteenth and seventeenth centuries. His installation has an overall beauty, but the viewer is also drawn to the individual, wonder-inspiring items within it, such as an 1863 underwater landscape painted by the Belgian artist Eugène de Ransonnet from within a diving bell, or a magnificent stuffed polar bear.

Close up, you see that the objects are categorized according to different - often nonscientific - criteria on different shelves. One grouping contains just teeth, another is of diverse objects assembled by one collector, another contains objects of similar colour. In this way, Dion aims to challenge the conventional mindset of the museum establishment.

But there is a sense of repetition here. Dion has created other such cabinets - his largest and most magnificent was for an exhibition celebrating 300 years of science in Berlin (Nature 467, 660; 2010). Paradoxically, he has become a darling of the very establishment he seeks to challenge.

Dion's overarching theme for Oceanomania is the contrast between our wonder at ocean biodiversity and fear that we are destroying it. Other Dion works on display include a model of a sturgeon - fished to near extinction for caviar - beached on a mound of discarded coins, and a stuffed flamingo coated in tar.

Given its location, Oceanomania is likely to attract thousands of visitors, which I hope will trigger sympathy for neglected historical collections elsewhere. The endorsement of a royal wedding will do it no harm. The bride, incidentally, also fits the aquatic theme: she is a former Olympic swimmer.

Alison Abbott is Nature's Senior European Correspondent. 